\title{
Pesticide knowledge, practice and attitude and how it affects the health of small-scale farmers in Uganda: a cross-sectional study
}

\author{
Anna H. Oesterlund*1, Jane F. Thomsen ${ }^{1}$, Deogratias K. Sekimpi² ${ }^{2}$ James Maziina², \\ Apio Racheal ${ }^{2}$, Erik Jørs ${ }^{3}$
}

1. Department of Occupational and Environmental Medicine, Bispebjerg Hospital, University of Copenhagen, Denmark

2. Uganda National Association of Community and Occupational Health (UNACOH), Kampala, Uganda.

3. Department of Occupational and Environmental Medicine, Odense University Hospital, Denmark

\begin{abstract}
Background: Over the past years there has been an increase in the use of pesticides in developing countries. This study describes pesticide use among small-scale farmers in Uganda and analyses predictors of pesticide poisoning (intoxication) symptoms.

Method: A cross-sectional study was conducted using a standardized questionnaire. Some 317 small-scale farmers in two districts in Uganda were interviewed about pesticide use, knowledge and attitude, symptoms of intoxication, personal protective equipment (PPE) and hygiene. The risk of reporting symptoms was analysed using logistic regression analysis.

Results: The most frequently used pesticides belonged to WHO class II. The farmers had poor knowledge about pesticide toxicity, and the majority did not use appropriate PPE nor good hygiene when handling pesticides. There was no significant association between the number of times of spraying with pesticides and self-reported symptoms of pesticide poisoning. The only significant association was between blowing and sucking the nozzle of the knapsack sprayer and self-reported symptoms of pesticide intoxication (OR: 2.13. 95\% CI: 1.09 - 4.18).

Conclusion: Unlike the practice in several other developing countries, small-scale farmers in Uganda do not use the most hazardous pesticides (WHO class 1a and 1b). However use of WHO class II pesticides and those of lower toxicity is seen in combination with inadequate knowledge and practice among the farmers. This poses a danger of acute intoxications, chronic health problems and environmental pollution. Training of farmers in Integrated Pest Management (IPM) methods, use of proper hygiene and personal protective equipment when handling pesticides should be promoted.
\end{abstract}

Keywords: acute pesticides poisoning (intoxication), small-scale farmers, developing country, knowledge, attitude and practice.

African Health Sciences 2014; 14(2):420-433

DOI: http://dx.doi.org/10.4314/ahs.v14i2.19

\section{Background}

The balance between population increase and sufficient food production is one of the most important challenges in many African countries, including Uganda [1]. The use of pesticides is an effective method to protect crops from being damaged and to improve yields [2]. Over the past years there has been an increase in the use of pesticides in developing countries, and the developing countries now account for about $20 \%$ of the worlds expenditure on pesticides [3]. However, improper use

\section{* Corresponding Author}

Anna H. Oesterlund

Department of Occupational and Environmental Medicine, Bispebjerg Hospital, University of Copenhagen, Denmark

Email address: anna_hobolth@yahoo.dk of pesticides can cause human poisonings, accumulate as residues in food and the environment, and lead to the development of resistance in pests $[4,5]$.

Approximately 200,000-300.000 people die worldwide from pesticide poisoning every year with the majority of deaths occurring in developing countries $[6,7]$. The main part of these deaths is due to self-poisoning (suicide). This is in perspective of 2-3millioncases of acute pesticide poisoning every year [8]. The Food and Agriculture Organisation of the United Nations (FAO) has tried to control the use of pesticides with its code of conduct $[12,7]$. For instance, FAO recommends that governments in developing countries promote pesticides that require little personal protective equipment [9-12]. Moreover The World Health Organisation (WHO) has made a Recommended Classification of Pesticides by Hazard categorising the pesticides according to health hazard, ranging from extremely hazardous to unlikely to present acute hazards [12]. This is a useful tool, especially for developing countries, for elimination of 
the most dangerous pesticides $[10,11]$. However, many pesticides used in developing countries are still listed as extremely and highly hazardous, for example, Jors et. al. have documented a frequent use of the most toxic pesticides among farmers in Bolivia, who have had no introduction on how to use pesticides and protect themselves against the dangers of intoxication [13]. Also, studies in African and Asian countries have shown use of unauthorised pesticides and a lack of advice on alternatives [7,14].

It is crucial that the use of pesticides is assessed to ensure that it does not harm humans or nature. Therefore the use of pesticides in developing countries should be further investigated and clarified, to provide guidance for governments and international organizations in making appropriate policies [8].

Many farmers in Uganda are small-scale farmers with less than a few acres per household. They are organized to help each other with selling of crops and with the distribution expenses, but they also exchange knowledge on farming. However small-scale farmers often farm without appropriate means or knowledge to use pesticides appropriately $[2,13,15]$. Incorrect dosage, incorrect timing and targeting, poorly maintained equipment, mixing with bare hands, lack of personal protective equipment (PPE (e.g. mask, boots, gloves, long sleeved shirt, overalls, hat)) and lack of hygienic precautions during and when spraying (e.g. not blowing or sucking nozzle, wash body after spraying, change clothes after spraying) may result in acute pesticide poisoning (APP) [16]. In the absence of appropriate handling of pesticides, not only the health of farmers, but also the health of their families is at risk $[14,17,18]$.

Studies have shown that it is beneficial to look at the knowledge, practice and attitude towards pesticide use. Yassin et. al in a study in the Gaza Strip have pointed to the fact that even though the farmers had high levels of knowledge on the health impact of pesticides they did not practice according to the knowledge they had. It is important to emphasize that clarifying these aspects makes it easier to take action where it is needed. This will over time minimize the hazards of occupational pesticide exposure [19].

The aim of this study was to determine the extent and character of pesticide use by small-scale farmers in Uganda, and to examine the knowledge, practice and impact of protective measures and the storage of pesticides. Furthermore, we analysed if increasing levels of pesticide exposure is a predictor for symptoms of acute pesticide poisoning.

\section{Method}

\section{Study design and setting}

This cross-sectional study constitutes the baseline of a three-year intervention study of farmers' pesticide use, health and environment in Uganda. The project is implemented by the Ugandan NGO Uganda National Association of Community and Occupational Health (UNACOH) in collaboration with the Danish nongovernmental organisation (NGO) Dialogos, and is funded by The Danish Ministry of Foreign Affairs.

The general objective of the intervention project is to reduce negative health effects of pesticides in humans and prevent pesticide pollution of the environment. The main elements of the intervention consist of educating farmers, extension workers and pesticide dealers in integrated pest management (IPM). IPM includes sound farming practices to reduce the use of pesticides to a minimum such as crop rotation, seed selection, pest identification, intercropping and the use of alternative non-chemical pest management methods [20,35].

The data collection was carried out from January to February 2011 in two different districts, Wakiso and Pallisa, in Uganda.. Wakiso primarily grows vegetables (groundnuts, tomatoes, green pepper etc.) and Pallisa primarily produces cotton. Forty to ninety percent of the farmers were expected to use pesticides $[1,15,17,20]$. Wakiso district, with a population of about $1.310,100$, is situated in the central part of Uganda, and surrounds the capital city, Kampala, close to Lake Victoria. Being close to Lake Victoria the Wakiso district is generally very fertile. Pallisa district, with a population of 394.000 people, is situated in the eastern part of Uganda, 170 kilometres from Kampala, close to the border with Kenya. Pallisa's climate is predominantly continental with a lot more sun and less rain than Wakiso. Unfortunately, the study data was gathered in Pallisa's dry season. This affected the outcome of our analyses as the spraying is generally more frequent in the wet season (March-May and October -November) due to higher pressure of insect pests, diseases and weeds.

\section{Participants}

In many African countries, farming is usually a business with all the family members engaged in the agricultural activities. It was a priority in the gathering of the study 
population to include enough women in the study sample to make gender-specific statistical analyses, since data on women and pesticides are currently very limited.

The project team, consisting of the project manager (EJ), the day to day project leader (DS), the research assistant $(\mathrm{AH})$ and Ugandan research assistants, visited and established contact with the local authorities in the two districts before starting the data collection. During these meetings, time and dates of the interviews were scheduled.

In each district a mid-level manager was connected to the project team. He or she was in charge of making contact with the local farmers and of making arrangements for interviewing. Both farmers organized in a farmers' group and farmers outside a group were included in the study. Interviews were conducted in the group leader's house, in the village hall, in member houses or in the field.

The sample included 150 farmers from each district making a total of 300 participants, out of a population of an estimated 6.000 in the 20 villages included in the study, giving a sample size of $5 \%$. This sample size was deemed sufficient to give a realistic picture of the situation on knowledge, attitude and practise among pesticide using farmers, based on experience from similar studies in other parts of the world $[13,36]$. The selection of farmers was done by convenience interviewing of 40 farmers who had been selected as representatives of farmer groups and those who showed up after being invited by a village farmer contact, a (snowballing) selection method not as good as random selection, but often used in studies in developing countries due to lack of person registers, appropriate directions of villagers and difficult accessibility.

\section{Standardized interviews}

All participants were interviewed individually using a standardized semi-structured questionnaire. The questionnaire with simple questions was developed on the basis of a questionnaire tested and used in similar studies in Latin-America and Nepal, showing good reliability and reproducibility with a kappa-score of $0.70[13,21,37]$. Translation from Spanish to English was done by a skilled translator and afterwards checked by another translator to check for correct translation.

Most questions were one of two types; either yes/no questions, offering a dichotomous choice, or multiple choice questions, offering several fixed alternatives. In addition to demographics and crop production, the questionnaire asked about types of pesticides used, knowledge of pesticides, attitude and practice during the mixing, application and storage of pesticides and toxicity symptoms. The pesticides used were subsequently classified according to the WHO Recommended Classification of Pesticides by Hazard, a classification used to distinguish the more and less hazardous forms of pesticides from each other based on the acute risk to human health, ranging from extremely hazardous (class Ia), highly hazardous (class Ib), moderately hazardous (class II), slightly hazardous (class III) to unlikely to present acute hazards (class U) [11].

There was a two-day training of interviewers, introducing them to the questionnaire, before starting the interviews. An important part of this training was to ensure that the interviewers understood the meaning of the questions, and to discuss possible ways to translate each question from English to the local languages.

A pre-test was carried out with 15 farmers in both Pallisa and Wakiso (not included in the sample), before modifying the questionnaire. The interviewers were young current or recently graduated Ugandan students from Makerere Univesity. Each question was translated on the spot by the interviewer from English into the local language during the interview. There was a twoday introduction to the questionnaire before starting the interviews. An important part of this training was to secure that the interviewers understood the meaning of the questions, and to discuss possible ways to translate each question from English to the local languages.

The project team members and advisors from School of Public Health and College of Agriculture of Makerere University reviewed the first couple of responses together with each interviewer, in an effort to minimise misunderstanding of questions and other interviewer errors.

All interviews were conducted face to face, and a trained interviewer would take approximately 30 minutes to complete an interview.

\section{Exposure variables}

Exposure to pesticides may be by inhalation of vapour, oral or direct dermal contact, with the latter being the most important entry route among farmers spraying pesticides. The main exposure variable was self-reported 
number of times sprayed the last month and the last season.

The frequencies of pesticides sprayed within the last month were divided into three groups: sprayed 1 time (reference group), sprayed 2-3 times and sprayed more than 3 times. People not spraying were left out of this part of the analyses, because they were not asked about symptoms in the last month. Pesticides used last season were divided according to the WHO classification of pesticides, making it possible to perform analyses on class II, III and U pesticides. Moreover, for class II pesticides we divided the number of times spraying into tertiles; spraying 1-7 times, 8-12 times and more than 12 times, using not spraying as the reference group. Class III and U pesticides were divided dichotomously into not spraying or spraying one or more times.

When using a knapsack sprayer to apply pesticides, the nozzle sometimes blocks. An additional exposure variable was whether the small-scale farmer would use his mouth to blow or suck in order to unclog the nozzle (yes/no).

\section{Outcome variables}

The questionnaire included three self-reported health outcome measures in relation to pesticide poisoning. As the first measure each farmer was asked if he or she had had any symptoms immediately after pesticide spraying in the last year, spontaneously mentioning all the symptoms they could recall ("spontaneous, last year"). Secondly the farmers were asked in the same way if they had experienced any symptoms immediately after spraying pesticides within the last month ("spontaneous, last month"). Finally, as the third measure, the farmers were once again asked if he or she had had any symptoms the last month, but now 18 different symptoms were read aloud, allowing the farmer to agree or disagree with each symptom ("asked, last month"). The reason for making both a "spontaneous" and an "asked" outcome measure was to eliminate possible recall bias. For all three outcome measures only symptoms potentially related to class II and III pesticides were included, which was 14 out of 18 symptoms. Each health outcome was aggregated into a dichotomous variable, with 0-1 symptom coded as 0 and more than one symptom coded as 1 . This was a choice made because many of the symptoms are frequent in other diseases as well $[13,22]$.

\section{Potential confounders}

Based on the literature the following set of potential confounder variables were included in all analyses: Age (continuous), gender (female/male), marital status (yes/no), farmer group (yes/no), educational level (no education/ primary school/>primary school), PPE (yes/no) and precautions (1-2/>2) [23]. In addition, district (Wakiso/ Pallisa) was included. Age was included as a continuous variable (linear and squared). PPE registered were: gloves, overalls, boots, mask, hat, longsleeved shirt. This variable was dichotomised (having no precautions / having one or more precautions)

\section{Statistical methods}

Descriptive statistics with means, standard deviation (SD) and range were used, for the total population and divided by district and gender. Increased levels of pesticide exposure (number of times sprayed the previous month / season and using mouth to unblock the nozzle) as predictors for reporting symptoms of acute pesticide poisoning were analysed using logistic regression. Both crude and adjusted odds ratios are presented.

Sensitivity analyses were performed with different cut points for number of times sprayed with pesticides and number of symptoms. Former studies have shown that gender and age can modify the effect of number of times sprayed in relation to acute pesticide symptoms $[13,19,24,25]$. Therefore we tested for interactions with gender and age, with both the interaction term and the main effects in the analyses. As differences in the two districts turned out to be significant, analyses with stratification were also carried out.

\section{Missing data}

Because data were gathered by interviews, missing variables were kept to a minimum, less than $3 \%$ on average. In the few cases of missing values, most of these are related to interviewers being unable to translate the question, respondents not understanding the question or typing errors.

\section{Ethical considerations}

The study was approved by the Makerere University School of Public Health Institutional Review Board (IRB), and then by the Uganda National Council of Science and Technology. The Helsinki declaration of ethical principles for medical research were followed [26]. Local leaders in each district sanctioned the study before data collection started. Participation in the study was voluntary; the participants were encouraged, but 
not forced, to be interviewed. All respondents were explained the purpose of the study, and after informed oral consent, written consent was also obtained from each participant. Those who could not write provided a thumb print as an indication of their consent.

\section{Results}

\section{Participants}

The total number of participants was 317. Table 1 provides the demographic details of the participants, distributed by district and gender. Participants from Pallisa were a little older than those from Wakiso. In general men were less not quite as often members of a farmers' group and their educational level was higher compared to the women. The average age was 42 years. The self-reported size of land used for crops ranged from $0.25-38$ acres (mean 4.15). A total of 306 (96\%) interviewed farmers were using pesticides and had been doing so with a mean of 17.5 years.

\section{Table 1}

Distribution by district, gender, farmers group, educational level and pesticide use of small-scale farmers in Wakiso and Pallisa, Uganda*.

\begin{tabular}{|c|c|c|c|c|c|c|}
\hline & & & Wakiso & Pallisa & Male & Female \\
\hline \multirow[t]{3}{*}{ District**: } & & $\mathrm{N}(\%)$ & $N(\%)$ & $\mathrm{N}(\%)$ & $\mathrm{N}(\%)$ & $\mathrm{N}(\%)$ \\
\hline & Wakiso & $155(49)$ & & & $87(52)$ & $64(48)$ \\
\hline & Pallisa & $161(51)$ & & & $102(54)$ & $58(46)$ \\
\hline \multicolumn{7}{|l|}{ Age } \\
\hline & $<29$ & $54(18)$ & $35(24)$ & $18(13)$ & $33(18)$ & $21(18)$ \\
\hline & $30-49$ & $150(51)$ & $71(48)$ & $78(53)$ & $98(51)$ & $52(45)$ \\
\hline & $>50$ & $91(31)$ & $41(28)$ & $50(34)$ & $49(31)$ & $42(37)$ \\
\hline \multicolumn{7}{|l|}{ Gender: } \\
\hline & Female & $123(39)$ & $64(43)$ & $58(36)$ & & \\
\hline & Male & $190(61)$ & $87(57)$ & $102(64)$ & & \\
\hline \multicolumn{7}{|c|}{ Farmers' group $* * *$} \\
\hline & Yes & $216(68)$ & $101(66)$ & $113(70)$ & $122(64)$ & $90(74)$ \\
\hline & No & $101(32)$ & $53(34)$ & $48(30)$ & $68(36)$ & $32(26)$ \\
\hline \multicolumn{7}{|l|}{ Educational level } \\
\hline & No education & $42(13)$ & $16(10)$ & $26(16)$ & $21(11)$ & $21(17)$ \\
\hline & Primary School & $143(45)$ & $76(49)$ & $66(41)$ & $85(45)$ & $56(46)$ \\
\hline & Secondary school & $112(36)$ & $54(35)$ & $57(36)$ & $73(38)$ & $38(30)$ \\
\hline & University & $4(1)$ & $4(3)$ & $0(0)$ & $1(1)$ & $2(2)$ \\
\hline & Other tertiary & $16(5)$ & $4(3)$ & $12(7)$ & $10(5)$ & $6(5)$ \\
\hline \multicolumn{7}{|l|}{ Use of pesticides } \\
\hline & No & $11(3)$ & $9(6)$ & $1(1)$ & $1(1)$ & $10(8)$ \\
\hline & Yes & $306(97)$ & $145(94)$ & $160(99)$ & $189(99)$ & $114(92$ \\
\hline
\end{tabular}

* Due to missing data the columns do not always sum up to the expected total

** Information regarding district was missing for one participant

*** Farmers' groups are characterized by 10 - 30 farmers organized to help each other with transportation and selling of crops to save money on distribution expenditures, but also with the purpose of exchanging knowledge on farming.

The 14 self-reported pesticides used by the farmers during the last month are shown according to the
WHO classification, and chemical class in Table 2. No pesticides were registered as extremely hazardous (Ia) or highly hazardous (Ib). 
Table 2

Classification of pesticides used by small-scale farmers in Wakiso and Pallisa Districts, Uganda.

\begin{tabular}{|l|l|l|l|l|l|}
\hline Pesticide & $\begin{array}{l}\text { Number } \\
\text { of } \\
\text { farmers* }\end{array}$ & Pallisa & Wakiso & $\begin{array}{l}\text { Toxicological class } \\
\text { fy WO }\end{array}$ & Chemical class \\
\hline Alpha-cypermethrin & 2 & 0 & 2 & II & $\begin{array}{l}\text { Overst pá formularen } \\
\text { Phenoxy-carboxylic-ac- } \\
\text { idNederst på formularen } \\
\text { Cypermethrin-profenofos }\end{array}$ \\
\hline Cypermethrin & 1 & 0 & 1 & II & Pyrethroid \\
\hline DDT & 52 & 13 & 34 & II & Pyrethroid \\
\hline Dimethoate & 1 & 1 & 0 & II & Pyrethroid \\
\hline Dimethylcyclopropanecarboxylic & 1 & 1 & 0 & II & Organochlorine \\
\hline Endosulfan & 1 & 0 & 1 & II & Organophosphate \\
\hline Fenvalerate & 1 & 1 & 0 & II & Organochlorine \\
\hline Lamda cyhalothrin & 11 & 6 & 5 & II & Pyrethroid \\
\hline Paraquat & 2 & 0 & 2 & II & Byrethroid \\
\hline Glyphosate & 14 & 1 & 13 & III & Phosphonomethyl \\
\hline Malathion & 1 & 1 & 0 & III & Organophosphate \\
\hline Mancozeb & 19 & 2 & 17 & U & Dithiocarbamate \\
\hline Unknown & 28 & 8 & 20 & & II \\
\hline
\end{tabular}

*The same farmer often uses several pesticides and spray with the same pesticide several times.

\section{Knowledge, practice and attitude}

Levels of knowledge among the farmers are presented in Table 3. Approximately one third (31\%) of the farmers have had training on how to use and handle pesticides. $289(92 \%)$ of the farmers think pesticides can have a negative effect on their health, $276(90 \%)$ know that the pesticide containers have marks showing the toxicity and $228(74 \%)$ say that they are able to read and understand these instructions. Despite these facts up to $122(40 \%)$ did not know the color coding of the pesticides. 
Table 3

Knowledge, safety practice and attitude during pesticide mixing, handling and application among small-scale farmers in Wakiso and Pallisa district, Uganda.

\begin{tabular}{|c|c|c|c|c|c|c|}
\hline & & All & Wakiso & Pallisa & Male & Female \\
\hline & & $\mathrm{N}(\%)$ & $\mathrm{N}(\%)$ & $\mathrm{N}(\%)$ & $\mathrm{N}(\%)$ & $\mathrm{N}(\%)$ \\
\hline \multicolumn{2}{|c|}{ Do you think pesticides can have a negative effect on your health? } & & & $(x(1)$ & & \\
\hline & No & $7(2)$ & $1(1)$ & 0 (4) & $3(2)$ & $4(3)$ \\
\hline & Yes & $289(92)$ & $144(95)$ & $143(88)$ & $173(91)$ & $112(94)$ \\
\hline \multirow{2}{*}{\multicolumn{7}{|c|}{$\begin{array}{l}\text { Can you read and understand instructions on the pesticide } \\
\text { containers? }\end{array}$}} \\
\hline & & & & & & \\
\hline & No & $70(23)$ & $27(18)$ & $43(27)$ & $40(21)$ & $30(26)$ \\
\hline & Yes & $228(74)$ & $114(78)$ & $113(71)$ & $145(77)$ & $80(69)$ \\
\hline & Sometimes & $10(3)$ & $6(4)$ & $3(2)$ & $4(2)$ & $6(5)$ \\
\hline \multicolumn{7}{|c|}{ Which sign marks the most dangerous pesticide? $*$} \\
\hline & I don't know & $122(40)$ & $75(51)$ & $47(30)$ & $63(33)$ & $57(40)$ \\
\hline & Blue color coding & $5(2)$ & $0(0)$ & $5(3)$ & $4(2)$ & $1(1)$ \\
\hline & Red color coding & $69(22)$ & $23(16)$ & $46(29)$ & $47(25)$ & $22(19)$ \\
\hline & Yellow color coding & $23(8)$ & $5(3)$ & $18(11)$ & $14(7)$ & $9(8)$ \\
\hline & Green color coding & $7(2)$ & $3(2)$ & $4(3)$ & $3(2)$ & $4(3)$ \\
\hline & Skull and bones pictorials & $\frac{75(24)}{70(23)}$ & $\frac{42(29)}{22(15)}$ & $\frac{31(20)}{48(30)}$ & $\frac{258(31)}{44(23)}$ & $\frac{17(15)}{25(22)}$ \\
\hline \multicolumn{7}{|c|}{$\begin{array}{l}\text { Have you ever had any training on how to use and handle } \\
\text { pesticides }\end{array}$} \\
\hline & $\mathrm{S}_{1}$ & $213(69)$ & $97(67)$ & $114(71)$ & $129(68)$ & $84(72)$ \\
\hline & Yes & $96(31)$ & $50(33)$ & $60(29)$ & $60(32)$ & $33(28)$ \\
\hline \multicolumn{7}{|c|}{ What do you wear doing pesticide spraying (PPE)? } \\
\hline & Ordinary clothing & $229(73)$ & $105(70)$ & $123(77)$ & $141(74)$ & $87(74)$ \\
\hline & Gloves & $38(12)$ & $24(16)$ & $14(9)$ & $18(9)$ & $20(17)$ \\
\hline & Overall & $26(8)$ & $14(9)$ & $12(8)$ & $16(8)$ & $10(8)$ \\
\hline & Boots & $160(51)$ & $109(73)$ & $49(31)$ & $108(57)$ & $51(43)$ \\
\hline & Mask & $39(31)$ & $34(23)$ & $5(3)$ & $19(10)$ & $20(17)$ \\
\hline & Hat & $26(8)$ & $19(13)$ & $7(4)$ & $17(9)$ & $9(8)$ \\
\hline & Long-sleeved shirt & $76(24)$ & $35(23)$ & $41(26)$ & $46(24)$ & $29(25)$ \\
\hline \multicolumn{7}{|c|}{ Do you take precautions immediately after handling pesticides? } \\
\hline & Yes & $304(98)$ & $145(97)$ & $157(99)$ & $187(98)$ & $120(98)$ \\
\hline & No & $6(2)$ & $4(3)$ & $2(1)$ & $3(2)$ & $2(2)$ \\
\hline \multicolumn{7}{|c|}{ How long does it take you to spray the field } \\
\hline & $<1$ hour & $93(30)$ & $23(16)$ & $70(44)$ & $56(30)$ & $37(32)$ \\
\hline & $1-3$ hour & $153(50)$ & $76(53)$ & $76(49)$ & $89(47)$ & $62(54)$ \\
\hline & $>3$ hours & $58(20)$ & $46(31)$ & $11(7)$ & $42(23)$ & $15(14)$ \\
\hline \multicolumn{7}{|l|}{ Do you use a knapsack sprayer: } \\
\hline & Yes & $287(93)$ & $131(89)$ & $154(96)$ & $175(93)$ & $109(93)$ \\
\hline & No & $21(7)$ & $15(11)$ & $6(4)$ & $13(7)$ & $8(7)$ \\
\hline \multicolumn{7}{|c|}{\begin{tabular}{|l|l|} 
In case you get a blockage of your sprayer nozzle what do you do? & \\
\end{tabular}} \\
\hline & $\begin{array}{l}\text { Use mouth to blow to } \\
\text { unblock }\end{array}$ & $61(20)$ & $26(19)$ & $35(23)$ & $37(20)$ & $23(20)$ \\
\hline & Use a sharp object to unblock & $160(55)$ & $92(65)$ & $66(43)$ & $106(55)$ & $52(47)$ \\
\hline & Replace with another nozzle & $74(25)$ & $22(16)$ & $52(34)$ & $47(25)$ & $26(23)$ \\
\hline
\end{tabular}

* In several of the questions the totals are not equal to the number of participants either because of missing data or because of the possibility of multiple answers. Ex more than 317 answered this question. 
Variation in level of knowledge for men and woman was small and pointing in random directions. However of the $93 \%$ who used a knapsack sprayer to mix and apply the pesticides, $22 \%$ of the males and only $12 \%$ of the females took more than three hours to spray their field.

Questions relating to personal protective equipment and precautions after using pesticides show that a high percentage $(73 \%)$ use ordinary clothing when spraying. The most commonly used PPE were boots (51\%), followed by long-sleeved t-shirts (24\%). Ninety-eight percent of the farmers take precautions after spraying pesticides.

The association between increasing levels of pesticide usage and self-reported symptoms

The prevalence of self-reported symptoms is shown in Figure 1. Skin irritation, headache, extreme tiredness, excessive sweating, blurred vision and dizziness are the most commonly reported symptoms.

Figure 1

Frequencies of symptoms relevant for class II and III pesticides reported by small-scale farmers, Wakiso and Pallisa, Uganda.

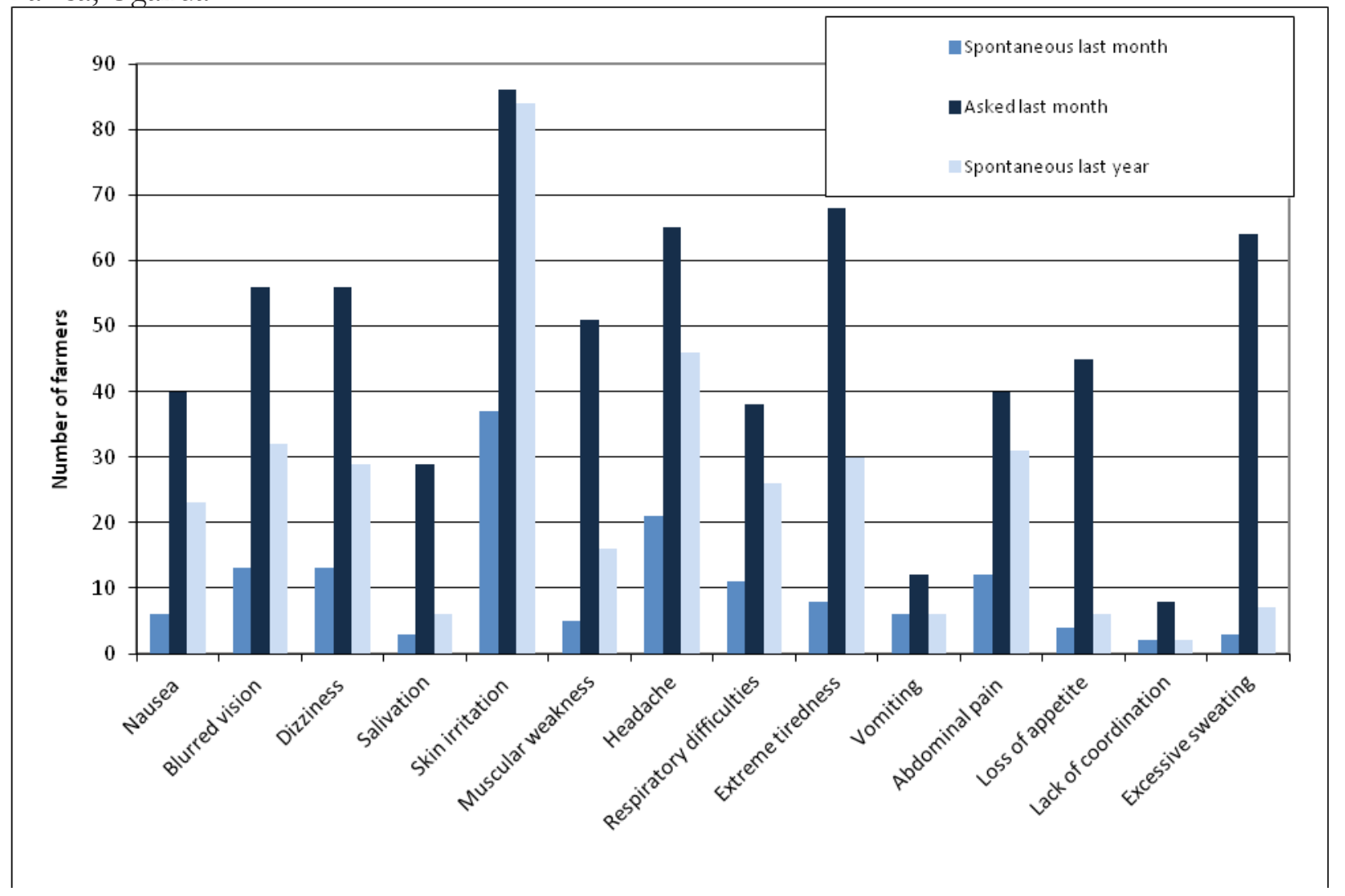

Table 4 shows if increasing levels of pesticide exposure, for class II, class III and class U pesticides, is a predictor for symptoms of acute pesticide poisoning immediately after spraying (last year) ( $\mathrm{N}=317$ participants). The pesticide classes are listed horizontally and the numbers of times sprayed and the covariates are listed vertically. The analyses show that number of times sprayed with each pesticide class is no predictor for self-reported symptoms. The effects of the covariates, which are also listed in table 4, show that farmers in the Pallisa district have an increased risk of having symptoms compared to farmers in the Wakiso district in all pesticide classes (e.g. class II: OR 2.7, 95\% CI: 1.3 - 5.2) independent of other factors (adjusted). Being in a farmers' group increased the risk of symptoms (e.g. class II: OR 2.2, 95\% CI: 1.2 - 4.2) where as being a woman reduces the risk (e.g. class II: OR 0.5, 95\% CI: 0.3 - 0.9). Farmers taking more precautions (continuous) had a significantly higher risk of reporting more than 1 symptom with an OR of 1.3 (95\% CI: $1.0-1.8)$ for class II pesticides than those not taking precautions. 
Table 4

Increasing levels of pesticide exposure and the risk of reporting spontaneously mentioned pesticide poisoning symptoms (last year). Risk estimates for the covariates are also shown.

Small-scale farmers in Wakiso and Pallisa district, Uganda $(\mathrm{N}=317)$. Significant findings in bold.

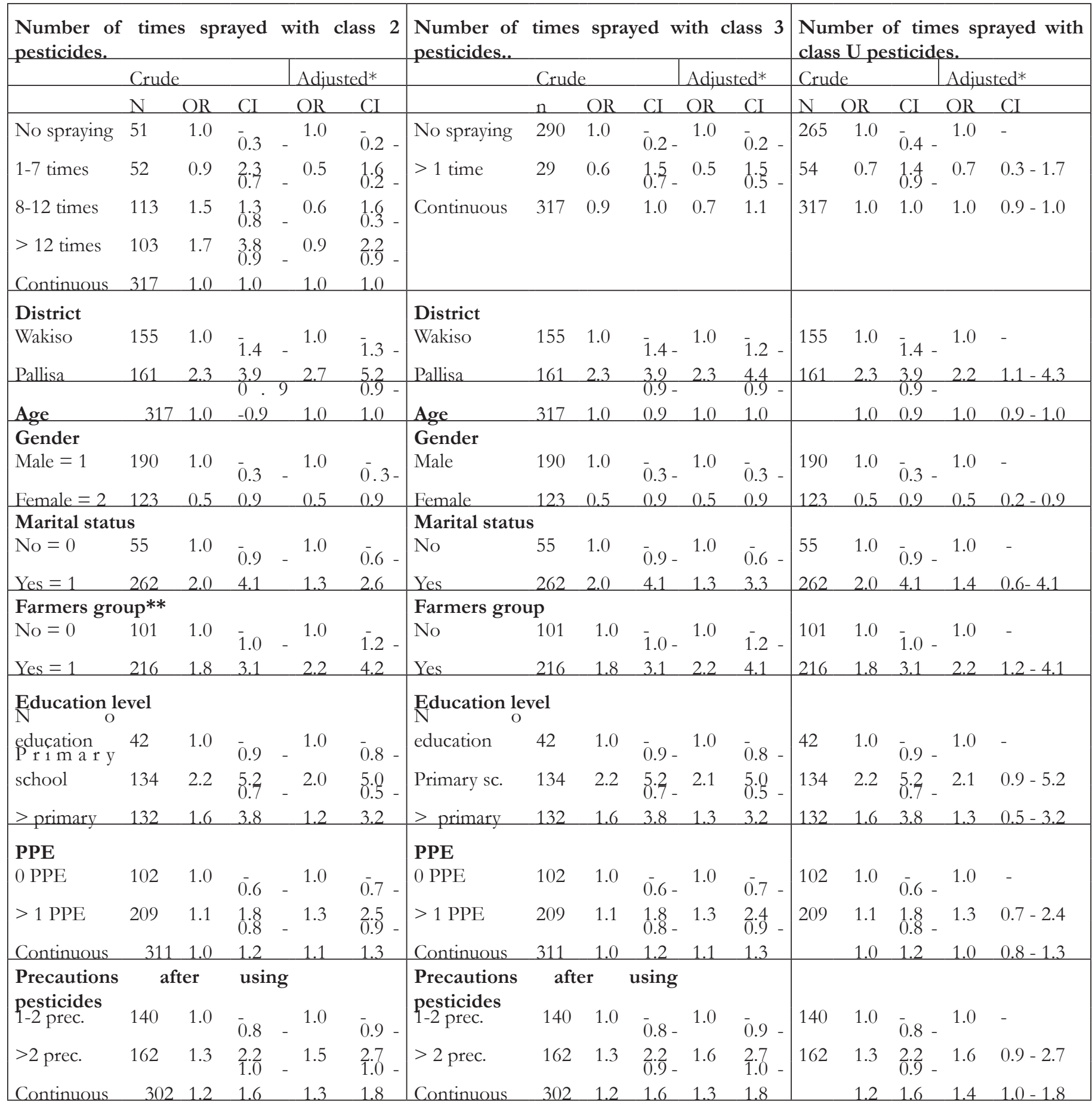

* The adjusted analyses include the following potential confounders: district, age gender, marital status farmer group, education level, use of PPE and precautions.

** Farmers' groups are characterized by 10 - 30 farmers organized to help each other with transportation and selling of crops to save money on distribution expenditures, but also with the purpose of exchanging knowledge on farming. 
Adjusted logistic regression analyses were also conducted on 171 of the participants who had sprayed within the last month (62 from the Pallisa district and 109 from the Wakiso district) but there were not significant association between numbers of times sprayed and symptoms of pesticide poisoning. There was an increased crude OR of 2.5 (95\% CI: 1.1 - 5.4) for spontaneously selfreported pesticide symptoms in Pallisa. After adjusting for potential confounders there was still no association between the number of times sprayed and self-reported pesticide symptoms, and the potential confounder 'district' was no longer significant.

Adjusted logistic regression analyses stratified on the two districts for class II pesticides did not change the association between the number of times sprayed and symptoms or the directions of the ORs in the confounder variables. When testing for interaction there were no significant findings. Changing the cut points for number of times sprayed and number of symptoms did not influence the odds ratios significantly.

The use of the mouth to unblock the nozzle (either blowing or sucking) was associated with a significantly higher risk of reporting acute pesticide poisoning within the last year with a crude OR of 2.5 (95\% CI: 1.4 -4.3). After adjustment (number of times sprayed was kept in the model) OR for class II pesticides was 2.1 (95\% CI: 1.1 - 4.2). The adjusted OR for symptoms reported spontaneously and asked (last month) was also elevated (OR 1.3, 95\% CI: $0.5-3.9$ and 1.6, 95\% CI: $0.5-4.6$ respectively), but not significantly.

We divided the symptoms into four categories: Neurological symptoms, abdominal symptoms, skin symptoms and respiratory symptoms. Logistic regression analyses for each symptom group controlling for the confounders did not show any significant association neither in the last month nor in the last year. Furthermore we did not find any significant associations when we examined the two most frequently reported pesticide poisoning symptoms, skin irritation and headache, one at a time.

\section{Discussion}

Our findings show that class II pesticides, mainly cypermethrin and cypermethrin-profenofos, are the most frequently used pesticides for small-scale farmers in two agricultural districts in Uganda.

This is an important finding, as other studies have shown extended use of class I pesticides in developing countries. In a cross sectional study by Jors et al. in Bolivia for small-scale farmers, it was shown that one of the frequently used pesticides is Methamidophos, which is classified as highly hazardous class Ib $[11,33]$. Also in Vietnam there has been an increased use of class I pesticides even though many of them are banned [28]. However a study made by Ngowi et. al. in Northern Tanzania, close to the border of Uganda, has shown a low quantity of class I pesticides; while a study made in Ghana indicates that small-scale farmers mainly used class II and III pesticides [32,4]. These studies suggest that African small-scale farmers are not as exposed to class I pesticides as Asian and Latin American farmers. A study made in Kenya found that mainly large scale farmers and not small-scale farmers used class I pesticides [29]. Nevertheless class II pesticides are still classified as moderately hazardous and known to have severe negative effect on human health and environment, and therefore other less dangerous alternatives should still be promoted [30]. In this study, twenty-eight small-scale farmers did not know the name of the pesticide they used. These could be highly hazardous chemicals. However, an observational study conducted concurrently in the same two districts among pesticide dealers and their stock of pesticides supports the finding that the pesticides used are mainly class II and pesticides of lower toxicity sold, as no class I pesticides were identified in the shops [27].

The most important reason for the farmer's choice of pesticide must be availability of pesticides. Availability is regulated by the Ministry of Agriculture and the Pesticide Importers Association who decide on what to allow and what to import. Then their choices are partly reflecting considerations on pesticide toxicity, pesticide efficiency, important pest problems and habits of pesticide use.

We expected that 40-90 \% of the farmers used pesticides, but the data showed that $97 \%$ did. This supports the fact that the use of pesticides is increasing in Africa, and will probably continue to do so as long as the population increases. Effective interventions need to be introduced to help the farmers get a sustainable relationship to pesticides $[10,12]$.

Another focus of this study was to examine the practices and impact of protective measures during use of pesticides. Most farmers used their normal clothes and less than one of six used any of the four protective measures: Gloves, overalls, masks or hats. This puts the 
environment and the health of the farmers and their families at risk [16]. Moreover many of the farmers in Pallisa and Wakiso did not know how to use and handle pesticides properly in line with other studies where small-scale farmers are shown to have some knowledge of the names and effects of the pesticides they use but lack knowledge about toxicity color codes and about proper mixing practices. [4, 13, 14, 15, 19]. A study by Yassin et. al. from the Gaza Strip shows that the farmers are unable to make good crop decisions and exercise proper practices, without adequate knowledge and practice on pesticide classification systems, application rates, re-entry periods, mixing and storage of pesticides [19].

Integrated Pest Management (IPM) has shown to have an effect on minimizing the use and improper practices during use of pesticides. IPM emphasizes theimportance of the growth of healthy crops and encourages natural pest control systems. It keeps the use of pesticides to a level that is affordable for the farmers and reduces the risk to humans and the environment while still yielding the expected outcome $[4,7,13,35,36]$.

This study hypothesized that increasing levels of pesticide exposure is a predictor for symptoms of acute pesticide poisoning. The results of the analyses do not support this hypothesis. After adjustment for relevant potential confounders no significant associations were found.

The lack of associations between number of times sprayed and pesticide poisoning symptoms could be due to numerous reasons. It is possible that the amount of pesticide sprayed was insufficient for an exposure effect to be detected, supported by the fact that the majority of the farmers took less than three hours to spray their field and only used the less toxic class II and III pesticides. Moreover only a few used organophosphates and carbamates which are the ones responsible for the most acute toxic symptoms. The main symptoms reported were skin irritation, headache, extreme tiredness, excessive sweating, blurred vision and dizziness which are consistent with other studies $[13,14,15,32]$.

Many of these symptoms could, however, also be due to other factors like hot climate, long exposure to sunlight or other diseases [31]. This might affect the association as the farmer might be exposed to these factors simultaneously. We could have eliminated some of this by focusing more on physical signs, making health care personal observe the farmers or with the use of blood tests. Dasgupta et al. call attention to the point that self-reported symptoms is a weak indicator for pesticide poisoning, and recommend use of measuring levels of blood acetylcholinesterase (AChE) instead [28]. However measuring AChE levels can be difficult to interpret and it only reflects exposure to organophosphates and carbamates [28], moreover performing blood-tests in a field setting with known high levels of blood borne infections, such as HIV and HepBV, also poses an unnecessary risk for the researchers.

We did find a constantly increased risk of reporting possible pesticide poisoning symptoms when living in Pallisa (OR 2.7, 95\% CI: 1.3 - 5.2). However, when stratifying into the two districts there was still no association between number of times sprayed and pesticide poisoning symptoms. The reason for the increased symptom reporting could be that Pallisa is a poorer and more remote area, not having the same access to health care and therefore a lower state of health than the population in Wakiso.

There has been expressed concern about female farmers spraying and the need for more data on gender differences in response to pesticides exposure $[1,24]$. Very few studies look at both genders in relation to pesticide exposure. Therefore it was a priority in this study to interview both male and female farmers. We found that women had a significantly lower risk of symptoms. Except for knowledge on colour coding, our study did not find significant differences in knowledge, attitude and practice between men and women. However, when it comes to spraying of pesticides, the knapsack sprayer (which was used by $93 \%$ of the farmers) is very heavy. Other studies have shown that it is mostly men carrying the knapsack sprayer, where women are more involved in transporting, weeding and harvesting [25,34,29]. If men carry the knapsack sprayer for a longer time than women, men will have a longer exposure time. This is consistent with the fact that $22 \%$ of the men, and only $12 \%$ of the women, carry the knapsack sprayer for more than three hours in this study.

We found that farmers organized in groups had an increased risk of reporting pesticide poisoning symptoms. This finding was not expected but could be caused by the fact that members of a farmers' group are more conscious of the potential risk of pesticides and therefore report more symptoms. This could also explain the contradictory findings regarding precautions. However, the group is of significant importance 
to the farmers when it comes to distribution and selling of pesticides, and must therefore be taken into consideration when performing interventions. There is a lack of studies looking at how the organization of farmers in groups affects the correlation between the use of pesticides and pesticide poisoning. It would therefore be recommended that other studies take this into account.

Furthermore, we looked at the exposure of blowing or sucking a clogged nozzle of the knapsack sprayer as this is a common procedure preformed by $20 \%$ of the farmers. This analysis showed a significant increased risk of reporting pesticide poisoning symptoms within the last year, controlling for potential confounders. Jors et. al. also found an increased OR of 4.00 (95\% CI 1.70-9.45) with the habit of blowing/sucking the nozzle of the knapsack sprayer when obstructed [13]. These results suggest that this routine, performed by one fifth of the farmers, should be targeted in the intervention.

The study has several weaknesses that should be taken into account when interpreting the results. There are problems in translation of the questionnaire not only from Spanish to English but also from English to local language in the interview situation. Even though interviews were carried out by trained interviewers, and the training emphasized understanding the questionnaire, it was not possible to ensure that the translation of the questionnaire was clear and understandable, as we couldn't fully control the translation. With more people performing the interviews it is almost impossible to secure stringency and homogeneity. By a written translation of the questionnaire into the local languages we might have been able to eliminate some interview bias. Moreover there could be selection bias as we did not perform a random selection of participants but used a convenient sampling method as explained above. Furthermore, the study is cross-sectional in design and therefore we cannot make any causal inferences. Future studies using e.g. exposure and symptom diaries would be able to address this issue.

As many of the findings describing the situation on pesticide use among small scale farmers in Uganda are also found in similar studies in other developing and neighbouring countries, we think this study is very valuable, especially as not many studies on this issue has been published from Uganda.

\section{Conclusion}

Unlike the practice in several other developing countries, small-scale farmers in Uganda do not use the most hazardous pesticides of WHO class $1 \mathrm{a}$ and $1 \mathrm{~b}$. However the use of WHO class II pesticides and those of lower toxicity is seen in combination with inadequate knowledge and practices among the farmers. These pose a danger of acute intoxications, chronic health problems and environmental pollution. Therefore training of farmers in IPM methods, the practicing of proper hygiene and the use of personal protective equipment (PPE) when handling pesticides should be promoted.

\section{List of abbreviations}

AChE: acetylcholinesterase, APP: acute pesticide poisoning, CI: confides intervals, FAO Food and Agriculture Organisation of the United Nations, OR: Odds Ratio, NGO: non government organisations, PPE: personal protective equipment, UNACHO: Uganda National Association of Community and Occupational Health, SD: standard deviation, WHO: World Health Organisation.

\section{Authors' contributions}

EJ was the project manager of the study and will be responsible for the future coordination of the project from Denmark. He contributed to design, data gathering, analysis and drafting of the paper. DKS is the project coordinator in Uganda. ASH, JM and AP participated in the gathering of data and ASH performed the statistical analyses. JFT participated in the design and coordination and supervised the statistical analyses and drafting of the manuscript. All authors have read and approved the final manuscript.

\section{Acknowledgement}

The authors express their gratitude to the small-scale farmers in Pallisa and Wakiso for participating in the study. The authors also thank the district managers in Pallisa and Wakiso for making it possible to gather the data in the two districts, and The Danish Ministry of Foreign Affairs for funding the project.

\section{References}

1. Naidoo S, London L, Rother HA, Burdorf A, Naidoo $\mathrm{RN}$, Kromhout H: Pesticide safety training and practices in women working in small-scale agriculture in South Africa. Occup Environ Med 2010, 67:823-828.

2. Mansour SA: Pesticide exposure -Egyptian scene. Toxicology 2004, 198:91-115.

3. Issa Y, Sham'a FA, Nijem K, Bjertness E, Kristensen 
P: Pesticide use and opportunities of exposure among farmers and their families: cross-sectional studies 19982006 from Hebron governorate, occupied Palestinian territory. Environ Health 2010, 9:63.

4. Ntow WJ, Gijzen HJ, Kelderman P, Drechsel P: Farmer perceptions and pesticide use practices in vegetable production in Ghana. Pest Manag Sci 2006, 62:356-365.

5. Clarke EE, Levy LS, Spurgeon A, Calvert IA: The problems associated with pesticide use by irrigation workers in Ghana. Occup Med (Lond) 1997, 47:301-308.

6. Sekiyama M, Tanaka M, Gunawan B, Abdoellah O, Watanabe C: Pesticide usage and its association with health symptoms among farmers in rural villages in West Java, Indonesia. Environ Sci 2007, 14 Suppl:23-33. 7. Konradsen F: Acute pesticide poisoning -a global public health problem. Dan Med Bull 2007, 54:58-59.

8. Konradsen F, van der HW, Cole DC, Hutchinson G, Daisley H, Singh S, Eddleston M: Reducing acute poisoning in developing countries -options for restricting the availability of pesticides. Toxicology 2003, 192:249261.

9. Dinham B: Growing vegetables in developing countries for local urban populations and export markets: problems confronting small-scale producers. Pest Manag Sci 2003, 59:575-582.

10. Eddleston M, Karalliedde L, Buckley N, Fernando R, Hutchinson G, Isbister G, Konradsen F, Murray D, Piola JC, Senanayake N et al.: Pesticide poisoning in the developing world--a minimum pesticides list. Lancet 2002, 360:1163-1167.

11. World Health Organization: The WHO Recommended Classification of Pesticides by Hazard. Stuttgart, Germany; 2009.

12. Food and Agriculture Organization: International Code of Conduct on the Distribution and Use of Pesticides. Rome; 2002.

13. Jors E, Morant RC, Aguilar GC, Huici O, Lander F, Baelum J, Konradsen F: Occupational pesticide intoxications among farmers in Bolivia: a cross-sectional study. Environ Health 2006, 5:10.

14. Williamson S, Ball A, Pretty J: Trends in pesticide use and drivers for safer pest management in four African countries . Crop Protection 2008, 27:1327

15. Salameh PR, Baldi I, Brochard P, Abi SB: Pesticides in Lebanon: a knowledge, attitude, and practice study. Environ Res 2004, 94:1-6.

16. Abate T, van HA, Ampofo JK: Pest management strategies in traditional agriculture: an African perspective. Annu Rev Entomol 2000, 45:631-659.

17. Sam KG, Andrade HH, Pradhan L, Pradhan A, Sones SJ, Rao PG, Sudhakar C: Effectiveness of an ed- ucational program to promote pesticide safety among pesticide handlers of South India. Int Arch Occup Environ Health 2008, 81:787-795.

18. Macfarlane E, Chapman A, Benke G, Meaklim J, Sim M, McNeil J: Training and other predictors of personal protective equipment use in Australian grain farmers using pesticides. Occup Environ Med 2008, 65:141-146.

19. Yassin MM, bu Mourad TA, Safi JM: Knowledge, attitude, practice, and toxicity symptoms associated with pesticide use among farm workers in the Gaza Strip. Occup Environ Med 2002, 59:387-393.

20. DIALOGOS: Large-scale Development project: Pesticide use, Health and Environment - Uganda 201012. Sdr. Boulevard 29, 5000 Odense C, Denmark; 2010.

21. Ospina JM, Manrique-Abril FG, Ariza NE: [Educational intervention concerning knowledge and practices regarding work-related risks in potato farmers in Boyaca, Colombia]. Rev Salud Publica (Bogota) 2009, 11:182190.

22. Micromedex 1.0 (Healthcare Series) [http://www. micromedex.dk/hcs/librarian]

23. Ngowi AV, Mbise TJ, Ijani AS, London L, Ajayi OC: Pesticides use by smallholder farmers in vegetable production in Northern Tanzania. Crop Prot 2007, 26:16171624.

24. Garcia AM: Pesticide exposure and women's health. Am J Ind Med 2003, 44:584-594.

25. Tomenson JA, Matthews GA: Causes and types of health effects during the use of crop protection chemicals: data from a survey of over 6,300 smallholder applicators in 24 different countries. Int Arch Occup Environ Health 2009, 82:935-949.

26. Declaration of Helsinki - Ethical Principles for Medical Research Involving Human Subjects [http:// www.wma.net/en/30publications/10policies/b3/]

27. Duus J: Brugen af pesticider og værnemidler i Uganda - 2011. Institut for Jordbrug og Økologi, KULIFE.; 2011.

28. Dasgupta S, Meisner C, Wheeler D, Xuyen K, Thi LN: Pesticide poisoning of farm workers-implications of blood test results from Vietnam. Int J Hyg Environ Health 2007, 210:121-132.

29. Ohayo-Mitoko GJ, Kromhout H, Karumba PN, Boleij JS: Identification of determinants of pesticide exposure among Kenyan agricultural workers using empirical modelling. Ann Ocсир Hyg 1999, 43:519-525.

30. Keifer MC: Effectiveness of interventions in reducing pesticide overexposure and poisonings. Am J Prev Med 2000, 18:80-89.

31. Matthews GA: Attitudes and behaviours regarding 
use of crop protection products -A survey of more than 8500 smallholders in 26 countries. Crop Protection 2007, 12:834

32. Ngowi AV, Maeda DN, Partanen TJ, Sanga MP, Mbise G: Acute health effects of organophosphorus pesticides on Tanzanian small-scale coffee growers. $J$ Expo Anal Environ Epidemiol 2001, 11:335-339.

33. Jors E, Gonzales AR, Ascarrunz ME, Tirado N, Takahashi C, Lafuente E, Dos Santos RA, Bailon N, Cervantes R, Baelum J et al.: Genetic Alterations in Pesticide Exposed Bolivian Farmers: An evaluation by analysis of chromosomal aberrations and the comet assay. Biomark Insights 2007, 2:439-445.

34. Ssekabembe CK, Odong TL: Division of labour in nakati (Solanum aethiopicum) production in central Uganda. African Journal of Agricultural Research 2008, Vol. 3:400

35. FAO: AGP - Integrated Pest Management, 2013. [http://www.fao.org/agriculture/crops/core-themes/ theme/pests/ipm/en/]

36. Jensen HK, Konradsen F, Joers E, Petersen JH, Dalsgaard A.: Pesticide Use and Self-Reported Symptoms of Acute Pesticide Poisoning among Aquatic Farmers in Phnom Penh, Cambodia. Journal of Toxicology. 2011.Vol. 2011, Article ID 639814,

37. Neupane D, Pesticides exposure and its health effects among farmers in Nepal. Master's thesis, University of Southern Denmark. Availed on request. 